\title{
Histocytological Correlation Study of Thyroid Gland Lesions
}

\author{
Dr. Mital J. Gamit ${ }^{1}$, Dr Sanjay R. Talwelkar ${ }^{2}$, Dr. Gauravi A. Dhruva ${ }^{3}$ \\ ${ }^{1}$ Third Year Resident, Department of Pathology, P.D.U. Medical College-Rajkot, Gujarat, India \\ ${ }^{2}$ Associate Professor, Department of Pathology, P.D.U. Medical College-Rajkot, Gujarat, India \\ ${ }^{3}$ Professor \& Head of the Department of Pathology, P.D.U. Medical College-Rajkot, Gujarat, India
}

\begin{abstract}
Background: There is some "grey zone "In thyroid cytology where the diagnostic efficacy declines sharply rendering it diffic ult to categorize the lesions results in discrepancy. Objective: The aim of the present study is to determine the sensitivity, specificity, and accuracy of FNAC in the diagnosis of thyroid lesions and to correlate cytological findings with histopathology. Material and Method: $A$ Prospective study of FNAC of thyroid lesions was carried out along with its histopathological correlation starting from $1^{\text {st }}$ October $2013 t$ o $30^{\text {th }}$ September 2015 at the P.D.U. Medical College and Hospital, Rajkot, Gujarat (India). Out of 886 thyroid lesions aspirated in cytol ogy, we studied 80 cases followed by histopathplogical examination. Results: The sensitivity, the specificity, accuracy, false positive rate, false negative rate of FNAC for the diagnosis of solitary thyroid nodules were 92.85\%, 98.48\%, 97.5\%, 1.56\%, 7.14\%. Conclusion: The fi ne needle aspiration cytology is a simple, safe, cost effective, time saving, and minimally invasive procedure with a high diagnostic yield accuracy, sensitivity and specificity.
\end{abstract}

Keywords: sensitivity, specificity, May-Grunwald-Giemsa(MGG), thyroiditis, Papillary ca

\section{Introduction}

Fine needle aspiration cytology (FNAC) is a simple, safe, co st effective, minimally invasive and outpatient procedure tha $\mathrm{t}$ provides specific diagnosis rapidly. it is also used as the ini tial screening test for diagnosis of thyroid noduls ${ }^{1}$

FNAC has allowed a dramatic decrease in unnecessary surge ries with thyroid nodular disease, enhancing the percentage of malignant operated nodule over $50 \%{ }^{2}$. The prevalence of $t$ hyroid nodules ranges from $4 \%$ to $10 \%$ in the general adult $\mathrm{p}$ opulation and from $0.2 \%$ to $1.2 \%$ in children ${ }^{3}$. The majority of clinically diagnosed thyroid nodules are noneoplastic; onl y 5 to $30 \%$, are malignant and require surgical intervention. ${ }^{4}$

\section{Materials and Methods}

A prospective study of FNAC of thyroid gland lesions was c arried out along with its histopathological correlation at Dep artment of Pathology, PDU Medical College and Hospital, R ajkot, Gujarat (India) during the $1^{\text {st }}$ October 2013 to $30^{\text {th }}$ Sep tember 2015. Total 886 cases of thyroid lesion aspirates wer e done and out of these, we studied 80 cases followed by hist opathological correlation. The FNAC was performed using a 21-23 gauge needle attached to a $10 \mathrm{ml}$ disposable syringe. Aspirates were smeared on clean slides and stained by $\mathrm{H}$ \& E (Hematoxylin and Eosin) and May-Grunwald-Giemsa(MG G) stains. For histopathology, the excised surgical specimen $\mathrm{s}$ were fixed in $10 \%$ formalin, then routinely processed and stained by Hematoxyline and Eosin (H\&E) stain.

We compared findings of FNAC and histopathology and cal culate the sensitivity, specificity, and diagnostic accuracy of FNAC for diagnosing neoplastic and non-neoplastic lesions.

\section{Result}

In FNAC $66(82.5 \%)$ cases were non-neoplastic and 14 (17. $5 \%$ ) cases were neoplastic [TABLE-1].Histopathological ex amination revealed that $65(81.25 \%)$ were non-neoplastic lesi ons and $15(18.75 \%)$ cases were neoplastic[TABLE-2].Amon $\mathrm{g}$ these lesions $4(5.0 \%)$ were cystic lesions, $8(10.0 \%)$ were th yroiditis, $48(60 \%)$ were colloid goiter, $5(6.25 \%)$ hyperplasti c thyroid lesions and $15(18.75 \%)$ were neoplastic lesions.[T ABLE-3].Histocytology correlation is shown in [TABLE-6], [Figure-3].Sensitivity of FNAC was $92.85 \%$,specificity was $98.48 \%$ and diagnostic accuracy was $97.5 \%$.[TABLE-7]

\section{Discussion}

FNAC is usually the first line of investigation, and other inv estigations like ultrasound examination, thyroid function test , thyroidscan and antibody levels are done subsequently with an aim to select patients who require surgery and those that can be managed conservatively. ${ }^{\mathbf{5}}$ In our study thyroid lesions found to be common between the age group of 31-40 years. [TABLE-4], [FIGURE-1]] Female were higher in frequency $(\mathrm{n}=71,88.75 \%)$ than male $(\mathrm{n}=09,11.25 \%)$.[TABLE-5],[FIG URE-2]

In our study, a high diagnostic efficacy of FNAC in diagnosi ng both non-neoplastic and neoplastic lesions was achieved. FNAC showed a sensitivity of $92.85 \%$, specificity of $9.5 \%$ a nd diagnostic accuracy of $97.5 \%$. These results were compar able to previously reported results. [TABLE-8 $]^{\mathbf{6 - 1 0}}$

\section{Conclusion}

The fine needle aspiration cytology is a simple, safe, cost eff ective, time saving, and minimally invasive procedure which can be used as an outdoor patient procedure or as a part of $s$ creening programme for the diagnosis of thyroid lesion with 


\section{International Journal of Science and Research (IJSR) \\ ISSN (Online): 2319-7064 \\ Index Copernicus Value (2013): 6.14 | Impact Factor (2014): 5.611}

a high diagnostic yield accuracy, sensitivity and specificity. FNAC is recommended as the first line investigation for the diagnosis of solitary thyroid nodule, especially in developing countries with limited resources, as it helps in differentiatin $\mathrm{g}$ lesions that require surgery from those that can be manage $\mathrm{d}$ otherwise. But FNAC has its limitations so final diagnosis and treatment pattern should be based upon histopathology.

Table 1: Cytological Diagnosis of Thyroid Lesions

\begin{tabular}{|c|c|c|}
\hline Cytological Diagnosis & No. of Cases & Percentage \% \\
\hline Non-Neoplastic Lesions & 66 & 82.5 \\
\hline Neoplastic Lesions & 14 & 17.5 \\
\hline Total & 80 & 100 \\
\hline
\end{tabular}

Table 2: Histologiical Diagnosis of Thyroid Lesions

\begin{tabular}{|l|l|l|}
\hline Histological Diagnosis & No. of Cases & Percentage \% \\
\hline Non-Neoplastic Lesions & 65 & 81.25 \\
\hline Neoplastic Lesions & 15 & 18.75 \\
\hline Total & 80 & 100 \\
\hline
\end{tabular}

Table 3: Histological Diagnosis:

\begin{tabular}{|c|c|c|}
\hline Histological Diagnosis & $\begin{array}{c}\text { No. of case } \\
\text { s }\end{array}$ & $\begin{array}{c}\text { Percentage } \\
\%\end{array}$ \\
\hline Cystic lesion & 4 & 5.0 \\
\hline Thyroditis & 8 & 10 \\
\hline Colloid goiter & 48 & 60 \\
\hline $\begin{array}{c}\text { Hyperplastic thyroid lesio } \\
\text { n }\end{array}$ & 5 & 6.25 \\
\hline Neoplastic lesions & $\mathbf{1 5}$ & $\mathbf{1 8 . 7 5}$ \\
\hline Follicular adenoma & 6 & 7.5 \\
\hline Follicular carcinoma & 2 & 2.5 \\
\hline Papillary carcinoma & 5 & 6.25 \\
\hline Medullary carcinoma & 1 & 1.25 \\
\hline Anaplastic carcinoma & 1 & 1.25 \\
\hline Total & $\mathbf{8 0}$ & $\mathbf{1 0 0 \%}$ \\
\hline
\end{tabular}

Table 4: Age Wise Distribution of Thyroid Lesions

\begin{tabular}{|c|c|c|}
\hline Age Range (yrs) & No. of cases & Percentage \\
\hline Up to 10 & 0 & 0 \\
\hline $11-20$ & 06 & 7.5 \\
\hline $21-30$ & 20 & 25.0 \\
\hline $31-40$ & 22 & 27.5 \\
\hline $41-50$ & 13 & 16.25 \\
\hline $51-60$ & 11 & 13.75 \\
\hline $61-70$ & 06 & 7.5 \\
\hline $71-80$ & 02 & 2.5 \\
\hline Total & 80 & $100 \%$ \\
\hline
\end{tabular}

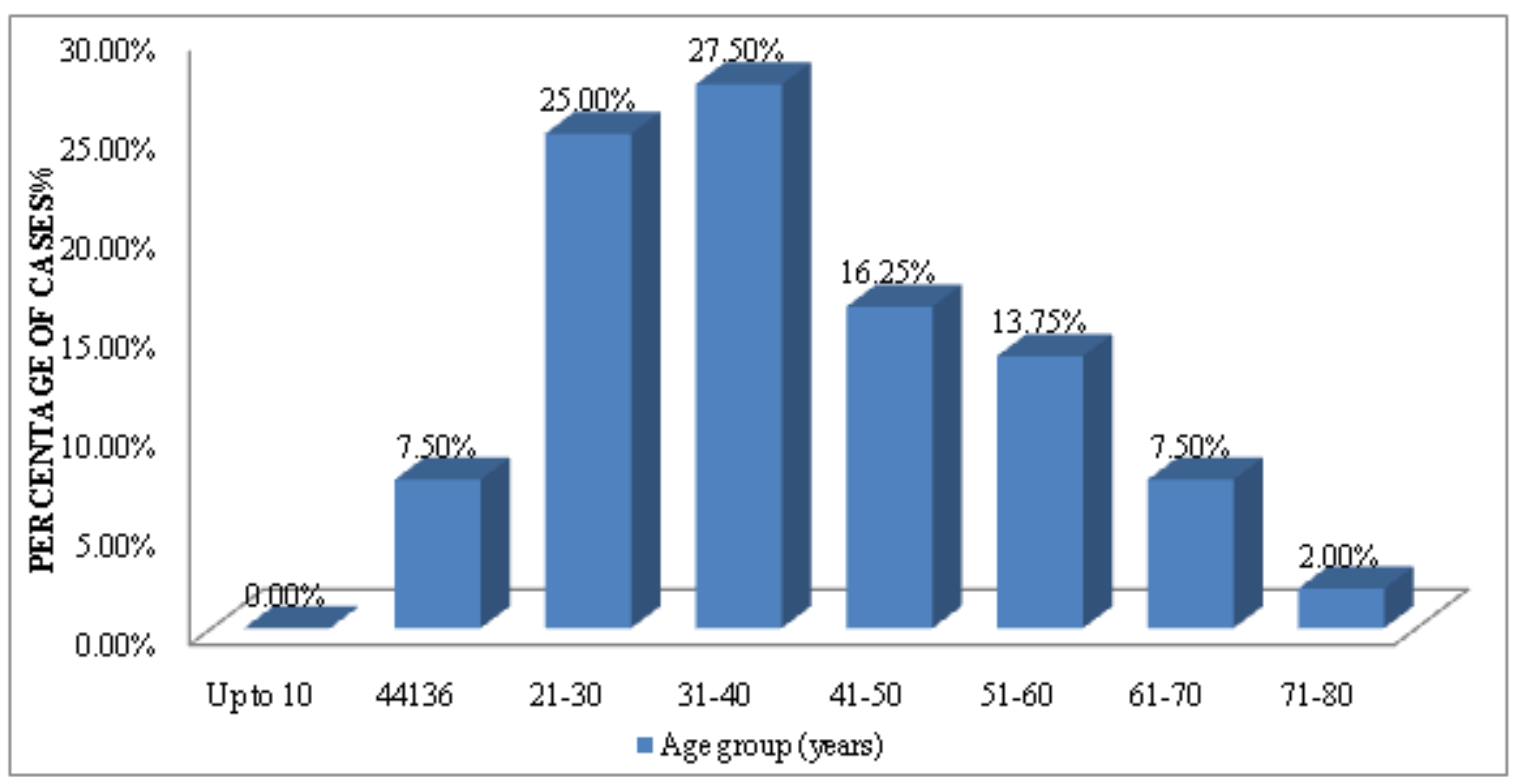

Figure 1: Age Wise Distribution of Thyroid Lesions

Table 5: Sex Wise Distribution of Thyroid Lesion

\begin{tabular}{|c|c|c|}
\hline Males & 09 & $11.25 \%$ \\
\hline Total & 80 & $100 \%$ \\
\hline
\end{tabular}

\begin{tabular}{|c|c|c|}
\hline Sex & No. of cases & Percentage \\
\hline Females & 71 & $88.75 \%$ \\
\hline
\end{tabular}




\section{International Journal of Science and Research (IJSR) \\ ISSN (Online): 2319-7064}

Index Copernicus Value (2013): 6.14 | Impact Factor (2014): 5.611

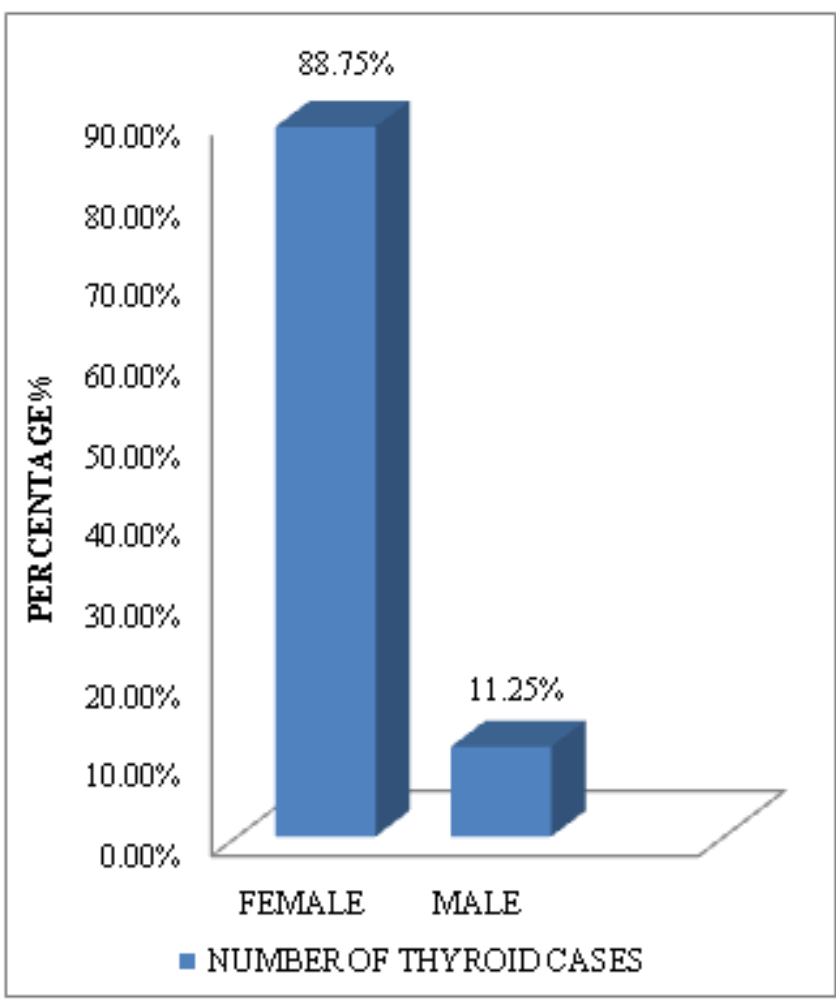

Figure 2: Sex Wise Distribution of Thyroid Lesion

Table 6: Cyto-Histopathological correlation of thyroid lesion of present study

\begin{tabular}{|c|c|c|c|c|c|c|c|c|c|c|c|c|c|}
\hline \multicolumn{2}{|c|}{ Cytological diagnosis and no. of cases } & \multicolumn{10}{|c|}{ Histopathological diagnosis } & \multirow[b]{2}{*}{ 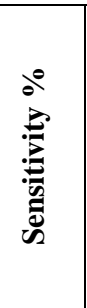 } & \multirow[b]{2}{*}{ 苞 } \\
\hline Diagnosis & No. & 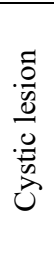 & 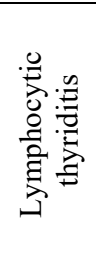 & 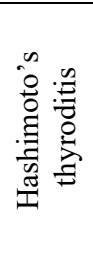 & 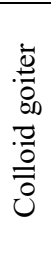 & 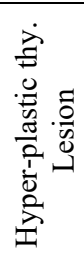 & 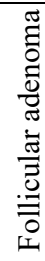 & $\begin{array}{l}0 \\
0 \\
\vdots \\
0 \\
.0 \\
0 \\
\end{array}$ & 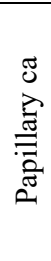 & 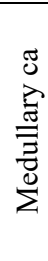 & 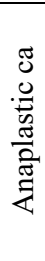 & & \\
\hline Cystic lesion & 5 & 4 & & & & & & & 1 & & & 100 & 80 \\
\hline Lymphocytic thyriditis & 5 & & 3 & 2 & & & & & & & & 100 & 60 \\
\hline Hashimoto's thyroditis & 3 & & & 3 & & & & & & & & 60 & 100 \\
\hline Colloid goite & 49 & & & & 46 & 2 & 1 & & & & & 95.83 & 93.87 \\
\hline Hyperplastic thy. Lesion & 4 & & & & 1 & 3 & & & & & & 60 & 75 \\
\hline Follicular neoplasm & 8 & & & & 1 & & 5 & 2 & & & & 87.5 & 87.5 \\
\hline Papillary ca & 4 & & & & & & & & 4 & & & 80 & 100 \\
\hline Medullary ca & 1 & & & & & & & & & 1 & & 100 & 100 \\
\hline Anaplastic ca & 1 & & & & & & & & & & 1 & 100 & 100 \\
\hline Total & 80 & 4 & 3 & 5 & 48 & 5 & 6 & 2 & 5 & 1 & 1 & & \\
\hline
\end{tabular}




\section{International Journal of Science and Research (IJSR) \\ ISSN (Online): 2319-7064}

Index Copernicus Value (2013): 6.14 | Impact Factor (2014): 5.611

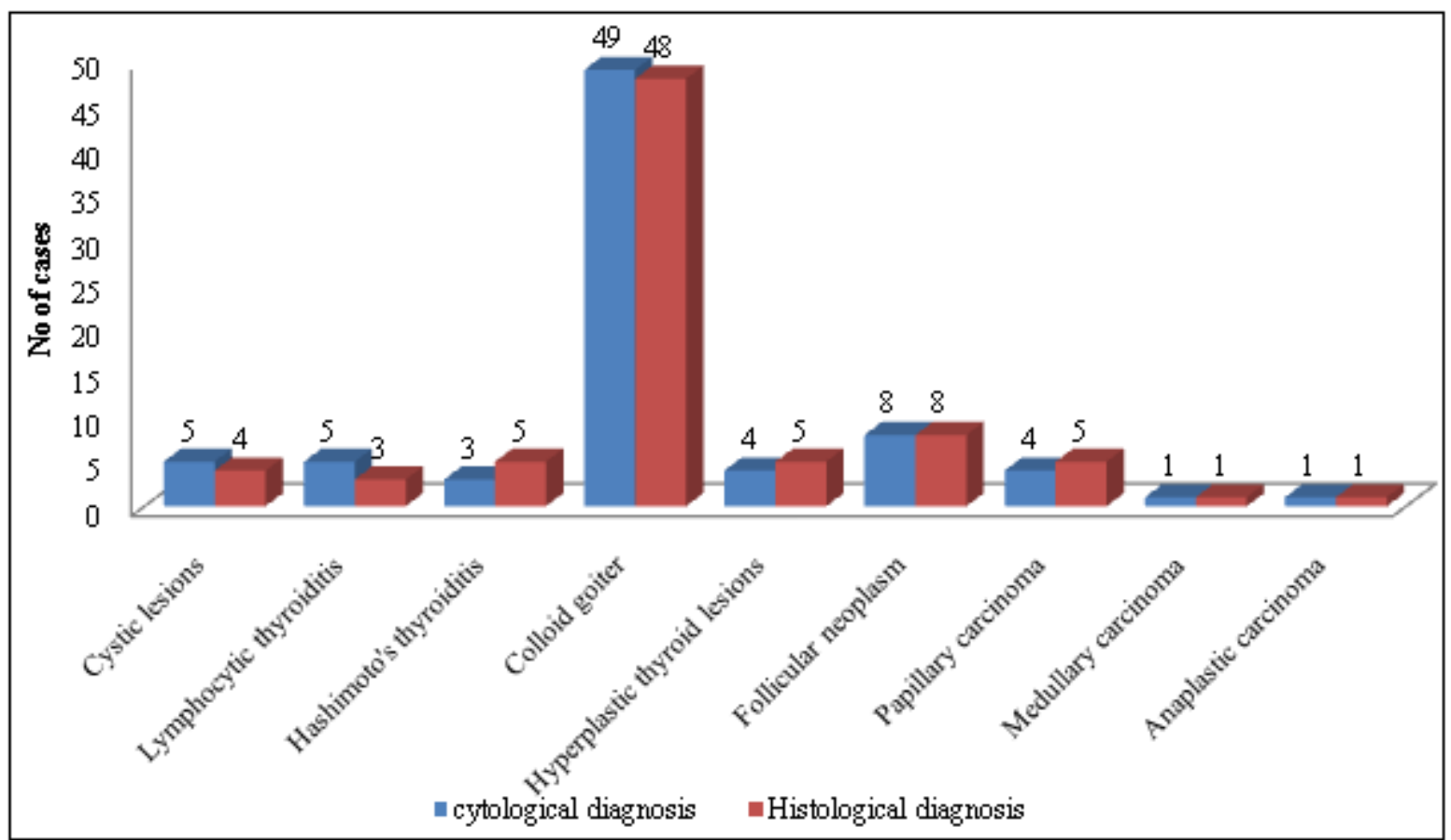

Figure 3: Cyto-Histopathological correlation of thyroid lesion of present study

Table 7: Diagnostic Efficacy of Thyroid Lesion of Present S tudy

\begin{tabular}{|c|c|c|c|}
\hline $\begin{array}{c}\text { Cytological } \\
\text { diagnosis }\end{array}$ & \multicolumn{2}{|c|}{ Histopathological diagnosis } & \multirow{2}{*}{ Total } \\
\cline { 2 - 3 } & Neoplastic & Non-neoplastic & \\
\hline Neoplastic & $13(\mathrm{a})$ & $01(\mathrm{~b})$ & $14(\mathrm{a}+\mathrm{b})$ \\
\hline Non neoplastic & $01(\mathrm{c})$ & $65(\mathrm{~d})$ & $66(\mathrm{c}+\mathrm{d})$ \\
\hline Total & $14(\mathrm{a}+\mathrm{c})$ & $66(\mathrm{~b}+\mathrm{d})$ & $\begin{array}{c}80(\mathrm{a}+\mathrm{b} \\
+\mathrm{c}+\mathrm{d})\end{array}$ \\
& & & \multicolumn{2}{|c}{} \\
\end{tabular}

Sensitivity $=a /(a+c) \times 100=13 / 14 \times 100=92.85 \%$

Specificity $=d /(b+d) \times 100=65 / 66 \times 100=98.48 \%$

Accuracy $=(a+d) /(a+b+c+d) \times 100=97.5 \%$

Percentage of false positive $=b /(b+d) \times 100=1 / 66 \times 100=1$. $56 \%$

Percentage of false negative $=c /(a+c) \times 100=1 / 14 \times 100=7$. $14 \%$

Table 8: Comparison of diagnostic value for malignant lesion

\begin{tabular}{|c|c|c|c|c|}
\hline Studies & Year & $\begin{array}{c}\text { Sensitivity } \\
\%\end{array}$ & $\begin{array}{c}\text { Specificity } \\
\%\end{array}$ & $\begin{array}{c}\text { Accuracy } \\
\%\end{array}$ \\
\hline Handa et al $^{\mathbf{6}}$ & 2008 & 97 & 100 & 98.48 \\
\hline Gupta et al $^{\mathbf{7}}$ & 2010 & 80 & 86.6 & 84 \\
\hline Pinky pandey et al $^{\mathbf{8}}$ & 2012 & 57.14 & 90 & 80.28 \\
\hline Parikh et al $^{\mathbf{5}}$ & 2012 & 71.43 & 100 & 90.24 \\
\hline Rupam et al $^{\mathbf{5}}$ & 2014 & 82.14 & 86.8 & 83.60 \\
\hline Present Study & 2015 & 92.85 & 98.48 & 97.5 \\
\hline
\end{tabular}

\section{References}

[1] Y. C. Oertel, "Fine-needle aspiration and the diagnosis of thyroid cancer," Endocrinology and Meabolism Clinics of North America, vol. 25, no. 1, pp.69-91,1996.

[2] Yassa L, Cibas ES, Benson CB, Frates MC, Doubilet $\mathrm{PM}$, Gawande AA, et al.Long term assessment of a multidisciplinary approach to thyroid nodule diagnostic evaluation. Cancer 2007;111:508-16.

[3] E. C. Ridgway, "Clinical evaluation of solitary thyroid nodules," in The Thyroid: A Fundamental and Clinical
Text, pp.1377-1385, G. B. Lippincott, Philadelphia, Pa, USA, 1986.

[4] R. Bakhos, S. M. Selvaggi, S. DeJong, et al., " Fine needle aspiration of thyroid: rate and cases of cytopathologic discordance," Diagn Cytopathol, vol. 23, no. 4, pp. 233-237, 2000.

[5] Giuffrida D, Gharib H. Controversies in the management of cold, hot and occult thyroid nodules. Am J Med 1995;99:642-50.

[6] Handa U, Garg S, Mohan H, Nagarkar N. Role of fine needle aspiration cytology in diagnosis and management of thyroid lesions: A study on 434 patients. Journal of cytology 2008

[7] Gupta M, Gupta S, Gupta VB. Correlation of Fine Needle Aspiration Cytology with Histopathology in Diagnosis of Solitary Thyroid Nodule. Journal of Thyroid Research, Volume 2010; Article ID 379051, 5 Pages.

[8] Pinki Pandey, Alok Dixit , Nanak C Mahajan. Fine needle aspiration of the thyroid: A cytohistologic correlation with critical evaluation of discordant cases. Thyroid Research and practice $2012 ; 9$. 2 :32-39.

[9] Parikh U.R., Goswami H.M., Shah A.M., Mehta N.P., Gonsai R.N. Fine Needle Aspiration Cytology(FNAC) Study of Thyroid Lesions(Study of 240 Cases). GUJARAT MEDICAL JOURNAL.2012;76 . 2: 25-30.

[10] Rupam Borgohain, Ranjeet Kumar Lal, Pritam Chatterjee, Nency Brahma,Swagata Khanna. A Study of Cyto-Histological correltion in the Diagnosis of Thyroid Swellind. Journal of Dental and Medical Science . 2014 ; 13 . 11, pp 46-49. 